\title{
Avoiding stranded bicycles in free- floating bicycle-sharing systems: Using survival analysis to derive operational rules for rebalancing
}

\section{Other Conference Item}

Author(s):

Guidon, Sergio; Tchervenkov, Christopher; Becker, Henrik; Axhausen, Kay W. (D)

Publication date:

2019-05

Permanent link:

https://doi.org/10.3929/ethz-b-000342814

Rights / license:

$\underline{\text { In Copyright - Non-Commercial Use Permitted }}$ 


\title{
Avoiding stranded bicycles in free-floating bicycle-sharing systems \\ Using survival analysis to derive operational rules for rebalancing
}

\author{
Sergio Guidon \\ Christopher Tchervenkov \\ Henrik Becker \\ Kay Axhausen
}

Conference Paper STRC 2019

\section{Abstract}

In order to optimize operations and increase revenue, free-floating (electric) bicycle sharing operators periodically move bicycles to high demand areas (a process known as rebalancing). As rebalancing is time and cost intensive, an important question that arises, is which bikes should be moved and which bikes are expected to be booked by the users within an acceptable period of time.

In this paper, two survival analysis methods are used to analyze the time until the occurrence of the next booking event: the Cox proportional hazards model and random survival forests. Locational characteristics, weather data, day of the week, as well as the number of other bikes in the vicinity are used to model time to booking.

Based on the results, the potential of survival analysis for improving operations of a freefloating (e-)bike sharing system is discussed. 